\title{
Nursery Irrigation System Checklist ${ }^{1}$
}

Tom Yeager ${ }^{2}$

Irrigation is a very important aspect of container plant production and must be intensively managed to achieve optimal production times for plants of superior quality. Inadequate irrigation often results in plants that exhibit slow growth, abnormal leaf color, and sparse foliage compared to plants that receive adequate water. While the symptoms of inadequate water seem distinct, excessive water might result in similar symptoms. Thus, there must be a balance between excessive and inadequate irrigation. Producers use irrigation control devices and past experience to achieve the balance; however, many potential pitfalls can occur when delivering or applying irrigation. This publication provides a checklist to assist producers with delivering water efficiently. A few simple checks can make a big difference in efficient and uniform delivery of the appropriate amount of water.

Check the irrigation system for missing components before turning it on. Determine if nozzles or other water-emitting devices, such as stakes or drip tubes, are missing. Missing nozzles not only result in wasted water, but they alter the pressure of the system, disrupting nozzle function. Nozzles and orifices should have the same specifications as those of the original design. A properly functioning nozzle is designed to operate or deliver a specified amount of water per unit of time at a predetermined operating pressure. Within an irrigation zone or area controlled by a single valve, the same nozzles and orifices with specific flow and pressure should be used. If nozzles with different-sized orifices use the same pressure as existing nozzles, then output changes and delivery is not uniform. However, exceptions could be made to equalize delivery between nozzles with different rotations or to compensate for pressure differences due to elevation changes. Pressure changes one pound per square inch for each two and one-third foot change in elevation. Pressure-compensating nozzles may be used to help ensure uniform irrigation.

Nozzles should be positioned and oriented appropriately without obstruction to ensure water delivery at the proper angle. For example, nozzles on risers or those hanging above the crop are positioned vertically so that water distribution is perpendicular to the riser or hanger and uniform across the surface of the containers. Microirrigation nozzles are positioned so that water is delivered onto or into the container substrate. In addition, ensure that water delivery is not obstructed by algae, plant foliage, or anything that will interfere with nozzle operation or water exiting the nozzle.

Before turning on the irrigation, look for leaks or leak indicators. A small flow of water is obvious, but indicators of leaks where water is not flowing require careful examination. Areas of inadequately irrigated plants or plants that are tipped from sudden high flow discharge can be indicative of malfunctions or burst pipes. Stains, the presence of algae or weeds, and substances or surfaces that remain moist are also leak indicators (Figure 1).

1. This document is ENH1208, one of a series of the Environmental Horticulture Department, Florida Cooperative Extension Service, Institute of Food and Agricultural Sciences, University of Florida. Original publication date April 2013. Visit the EDIS website at http://edis.ifas.ufl.edu.

2. Tom Yeager, professor, Environmental Horticulture Department, Florida Cooperative Extension Service, Institute of Food and Agricultural Sciences, University of Florida, Gainesville, FL 32611. 


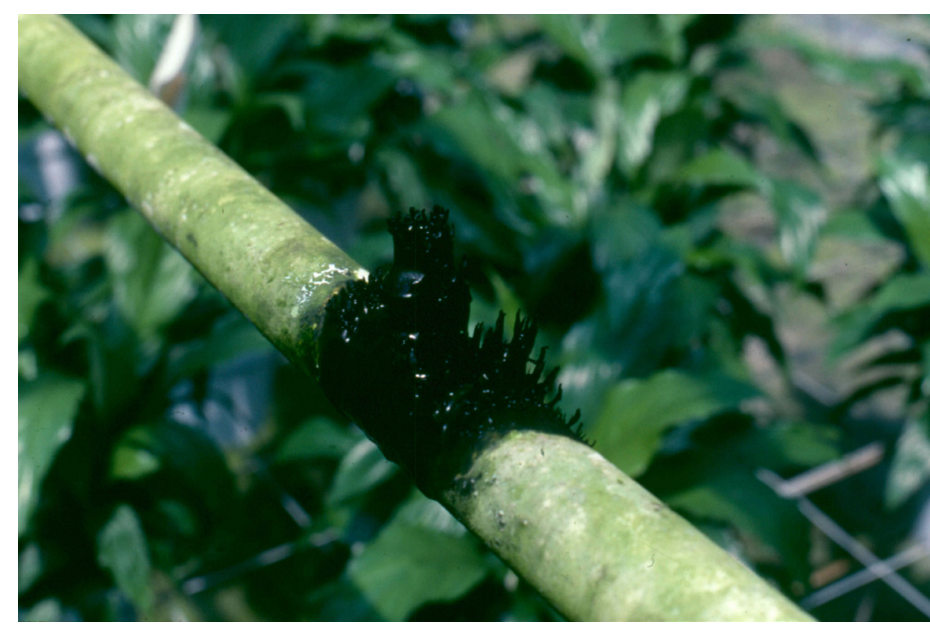

Figure 1. Algal growth is present on a nozzle that remains moist when the system is not operating. Credits: Tom Yeager

During irrigation start, operation, and shutdown, watch the nozzles, water flow, and distribution. As pipes fill with water, friction retards water movement. Pressure or force exerted by water works to overcome the friction and propel water along the length of pipe. The longer a pipe or distance the water travels, the greater the loss in water pressure from friction. A small-diameter pipe has more friction or pressure loss per unit length of pipe than a larger-diameter pipe. Therefore, an irrigation system must be designed with proper pipe sizes. Not only does a long distance result in the opportunity for a lot of friction, it also means that nozzles close to the water source are likely to begin operating before nozzles farther away from the water source. Consequently, those plants at the beginning of water delivery or nearest the water source receive irrigation before those farther away. This scenario is difficult to manage because plants close to the water source may receive too much water, and plants farther away may not receive enough water. A properly designed system with pressure regulators (Figure 2) or pressure-compensating nozzles can minimize differences in irrigation volume applied throughout the irrigated area. The differences in water applied throughout the area are measured by conducting a uniformity test. See the reference section of this publication for resources detailing the procedure for conducting uniformity tests.

It can be expensive to replace or retrofit an existing irrigation system to achieve uniform delivery. An option is to place small plants with low daily water requirements in locations where small irrigation volumes are applied and place large plants with high daily water requirements in locations where large volumes are applied.

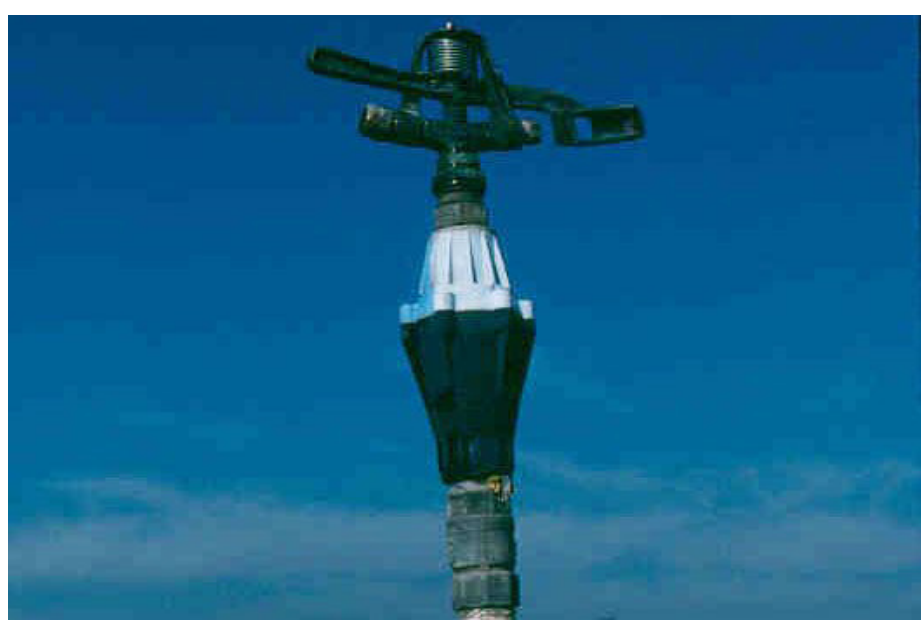

Figure 2. Appropriate nozzle operating pressure is achieved with a subtending regulator. Credits: Tom Yeager

During system operation, irregular flow or irregular patterns of water delivery are an indication of improper system function. These irregularities could be because of inherent differences in water pressure related to system design, clogged orifices, obstructions, or worn, irregular-shaped orifices that result in variable water pressure. Orifice size may be checked with the blunt end of a drill bit of appropriate caliber (Figure 3). A pitot tube with pressure gauge can be used to check pressure as the water flows from the orifice (Figure 4). During system operation, watch the arc or angle of water delivery to ensure it is appropriate. Irrigation should adequately cover the edges of benches or beds of plants. Rotating nozzles should move consistently with the

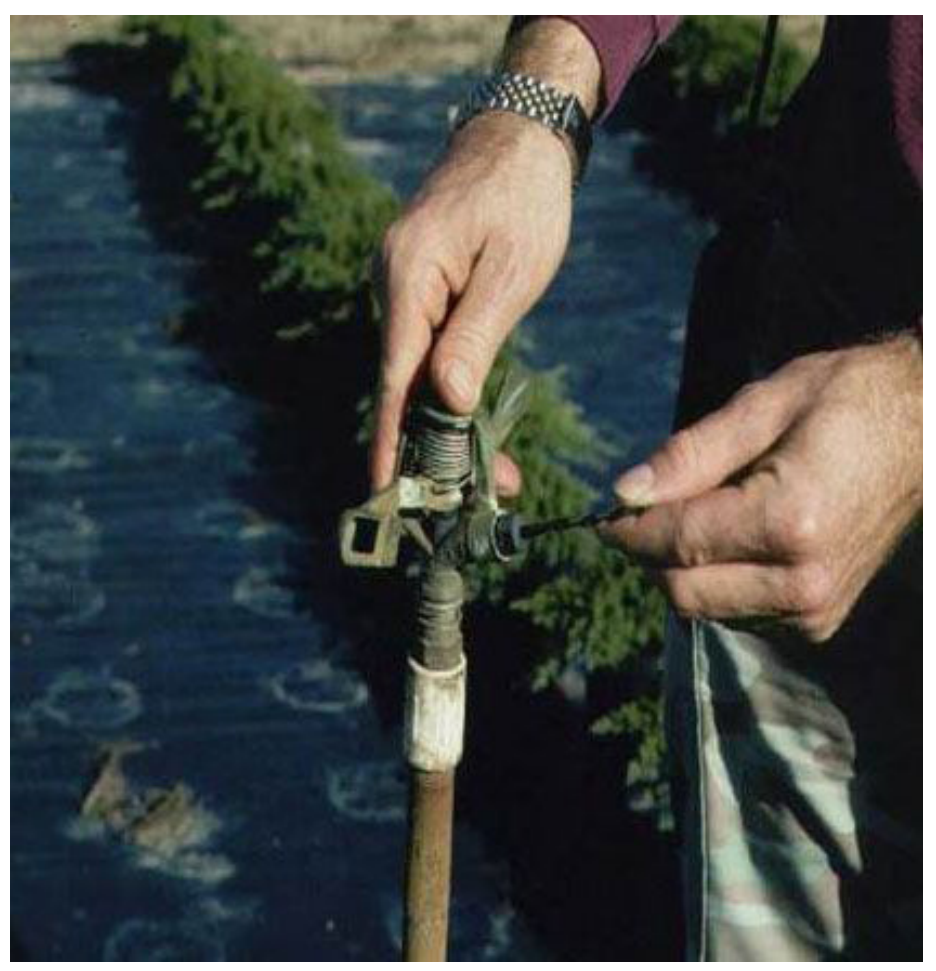

Figure 3. The blunt end of a drill bit with appropriate caliber is used to check orifice wear. Credits: Tom Yeager 


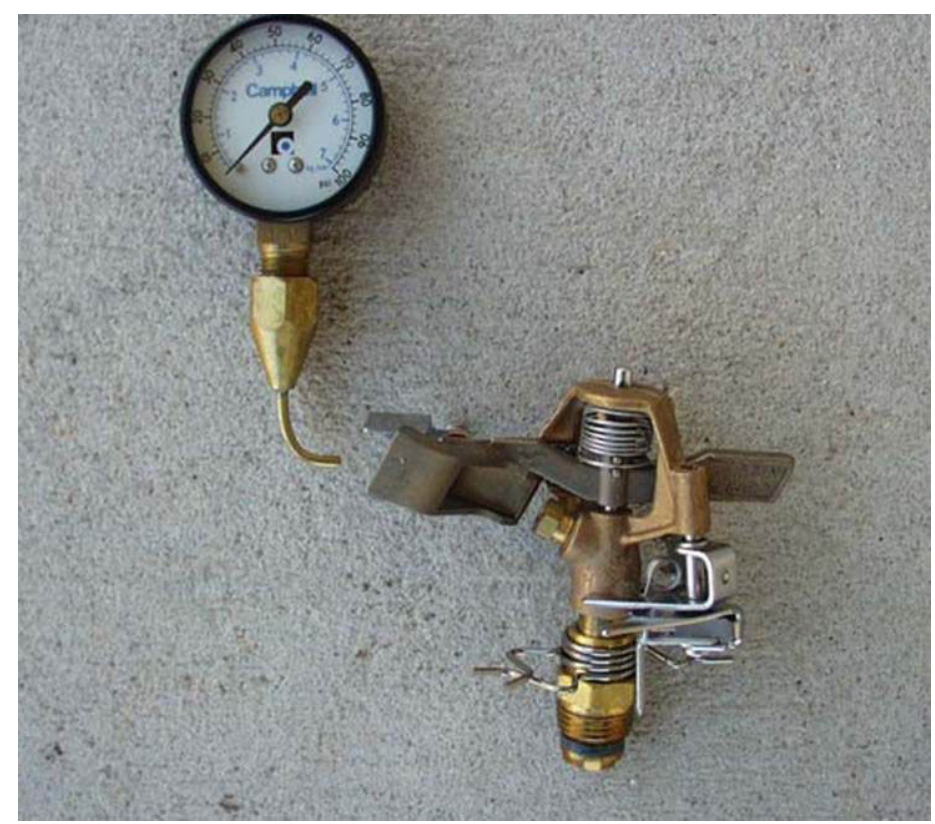

Figure 4. A pitot tube with pressure gauge is used to monitor pressure as water flows from the orifice. Credits: Tom Yeager

same number of rotations per minute. Also, check for leaks while the system is pressurized and operating.

As the system shuts down, watch the pattern of water exiting the nozzles and note the duration of flow. Nozzles located at lower elevations may continue to emit water for several minutes with a concentrated stream rather than a dispersed pattern. In addition to the excess water applied, this concentrated stream can damage tender plants and displace substrate from containers. Low-pressure drains on the ends of pipes at the lowest elevations allow pipes to drain rapidly so that duration of water delivery is minimized after irrigation ceases (Figure 5). Antidrip nozzles perform a similar function.

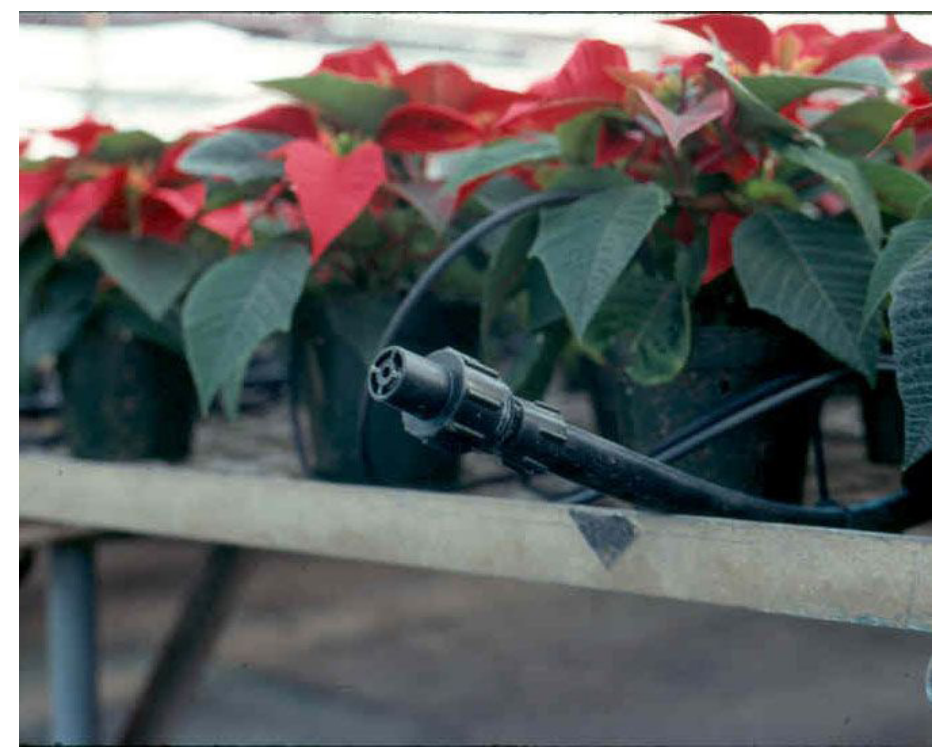

Figure 5. A low-pressure drain on the end of a pipe allows the pipe to drain rapidly when irrigation ceases. Credits: Tom Yeager
During system operation or water delivery, monitor the amount of water applied. This can be done with meters or reservoirs (vessels) for collecting water (Figure 6). Reservoirs should be placed strategically throughout the irrigated area. Ensure that reservoirs are not obstructed by plants or other objects. Measure and record water volume shortly after irrigation. An ideal approach is to note the location of each volume. Volumes should be similar to those calculated based on the nozzle manufacturer's output specification for the amount of time the system operated. The volume collected per unit of time is the irrigation application rate and should be consistent in time if operated under the same conditions.

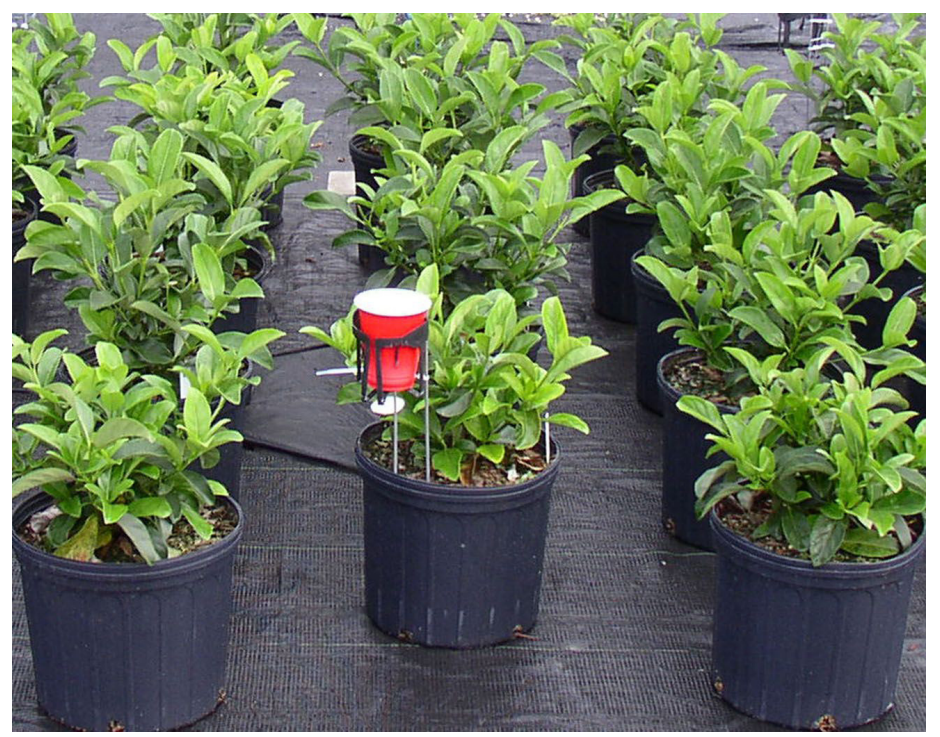

Figure 6. Reservoirs are used to monitor the irrigation application amount. Credits: Tom Yeager

The amount of water applied or the operation time should be adjusted to minimize the volume of leachate or water exiting the container. Reservoirs that exclude direct entry of overhead sprinkler water are placed under containers and used to collect leachate (Figure 7). One can quickly look to see if there are obvious differences in the leachate amount in the reservoirs. Leachate volumes should be similar for plants that are small relative to container substrate surface area. However, differences in leachate volumes do not indicate lack of uniform delivery. Leachate volumes may vary because plants extracted different amounts of water from the substrate, the substrate physical properties varied with time, or canopies of large plants influenced the amount of water entering the container substrate.

Simple checks performed before and during irrigation can make a difference in the effectiveness of irrigation and result in more efficient use of personnel time. A checklist is provided below. 


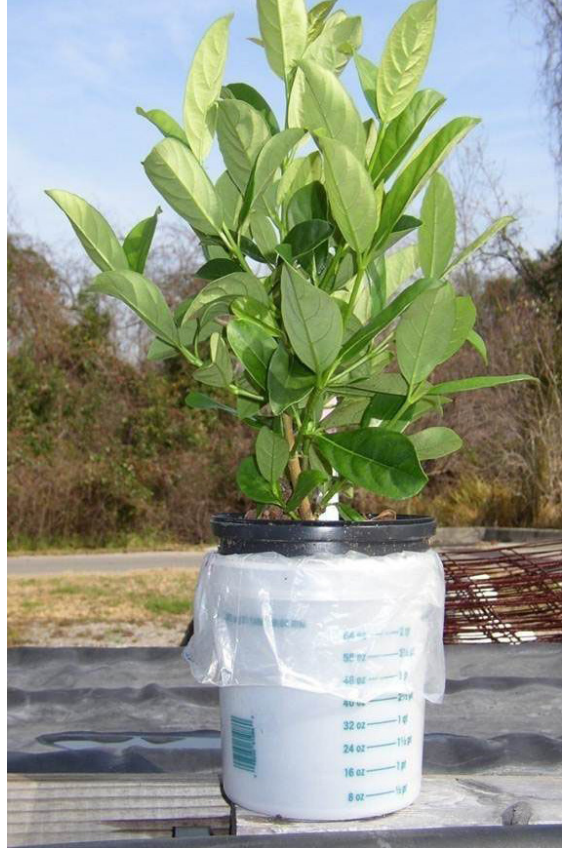

Figure 7. A plastic sleeve secured around a container with a rubber band prevents irrigation water from entering the reservoir along the container sidewall. Credits: Tom Yeager

\section{Irrigation Checklist}

\section{Before irrigation}

$\sqrt{ }$ Check for missing components.

$\sqrt{ }$ Determine that nozzles and orifices have the same specifications as original design.

$\sqrt{ }$ Ensure that nozzles are positioned and oriented appropriately, without obstruction.

$\sqrt{ }$ Look for indications of leaks.

\section{During irrigation}

$\sqrt{ }$ Watch nozzles operate to determine appropriate function.

$\sqrt{ }$ Conduct tests to verify uniform water delivery.

$\sqrt{ }$ Look for leaks.

$\sqrt{ }$ Determine if flow from nozzles ends immediately when operation terminates.

$\sqrt{ }$ Monitor amount applied.

$\sqrt{ }$ Note volume applied per unit of time because that is the application rate.

$\sqrt{ }$ Check that volume applied is consistent with each similar irrigation event.

$\sqrt{ }$ Adjust operational time to achieve minimal leaching.

\section{References}

Haman, D. Z, and T. H. Yeager. 2012. Field Evaluation of Container Nursery Irrigation Systems: Uniformity of Water Application in Sprinkler Systems. FS98-2. Gainesville: University of Florida Institute of Food and Agricultural Sciences. http://edis.ifas.ufl.edu/ae194.

Haman, D. Z., and T. H. Yeager. 2012. Field Evaluation of Container Nursery Irrigation Systems: Measuring Uniformity of Water Application of Microirrigation Systems. FS981. Gainesville: University of Florida Institute of Food and Agricultural Sciences. http://edis.ifas.ufl.edu/ae193.

Million, J., and T. Yeager. 2012. Measuring the Irrigation Requirement of Container-Grown Nursery Plants. ENH1197. Gainesville: University of Florida Institute of Food and Agricultural Sciences. http://edis.ifas.ufl.edu/ep458. 